\title{
Implantation of Digital Technology in Engineering Education as an Example of Study at Bauman Moscow State Technical University Discipline Materials" "Technology of Construction
}

\author{
Anatoly F. Tretyakov ${ }^{1}$, Mikhail A. Serezhkin ${ }^{1 *}$, and Kirill M. Zubarev ${ }^{1}$ \\ ${ }^{1}$ Bauman Moscow State Technical University, 2nd Baumanskaya str., 5/1, 105005, Moscow, Russia
}

\begin{abstract}
The article considers the possibility of using online courses in higher engineering education in order to increase its effectiveness. The organizational and methodological aspects of e-learning at the university are considered, the features of the development of an online technological course are analyzed. Based on a study of the best foreign and Russian practices, the authors suggest a possible option of combining traditional full-time education using an electronic lecture course with voice-overs by a teacher and an automated knowledge control system for students hosted on the Open BMSTU platform.
\end{abstract}

\section{Introduction}

Over the past decade, education has gone through an era of radical change. Until recently, it was the most conservative area of human activity and was little susceptible to the changes that society was undergoing. Nevertheless, the situation changed dramatically and the sources of such changes were the development and use of information and communication technologies in the field of education $[10,12,17,18,20]$.

The existing online technologies, with their correct application, can significantly increase the effectiveness of training, making it more flexible, practical and studentoriented. Among online courses, three levels can be distinguished [1].

The first level is an ordinary "remote" course taught by a teacher in one place, and students listen to it in another place or even in several places. Real-time distance courses provide the opportunity to use the resources of highly qualified teachers to a larger audience than usual.

The second and third levels are specially recorded online courses for repeated use, which, as a rule, include a certain apparatus for monitoring the work of students. Such courses can be both for a limited circle of users, and for an open audience who call online courses within the university. These courses are similar to a textbook, and students learn using the results of teachers' work.

*Corresponding author: serezhkin@bmstu.ru 
In classic online courses, the teacher is "in the frame" and is the central figure in the learning process. The active use of electronic resources is based, as a rule, on the use in training: video recordings of lectures and slide lectures with audio comments.

Video recording of lectures, according to the authors, [2] with the proper quality of recording and editing, can present educational material in the format of cognitive television broadcasts. But creating a course of appropriate quality is a laborious and expensive task. Attempts to save money lead to lecture notes in the form of a "talking head". Such video materials are hard to perceive and are often not in demand by students.

Slide lectures are less expensive, but at the same time popular with students, the lecture format. The teacher voices each slide that he prepared on the topic. Then, the relevant services responsible for the preparation of electronic educational resources process the received material add questions for self-monitoring, tests and form an interactive slide lecture. Animations, video clips from educational, documentary and promotional films are far from a complete list of reinforcing methodological elements of an online course that are not new to education. Therefore, the novelty of the online course is not obvious; it is a new combination of known elements [15, 19].

Other factors form the new reality: a qualitatively new accessibility of students to electronic resources in real time thanks to the Internet. E-learning is popular not only among students, but also already established specialists in their field who want to expand their knowledge in a particular area. More and more companies are switching to online learning forms with elements of gamification, as they not only save the funds allocated for training employees, but also allow staff not to break away from the work process. Humification is a promising direction in the development of technical education [13, 21, 22].

The online course can also be considered as an additional study guide in the subject that students study in the traditional form of training. At the same time, a system should be provided for automatic assessment of the assimilation of the studied material by weekly and final testing.

Online lecture courses conducted in a traditional form should be accompanied by reinforcing seminars at which various tasks are solved and consultations are carried out on homework.

Placing online courses on the "National Open Education Platform" is a way for the university and teachers to introduce themselves, to show society that they are able to provide high-quality education not only for students, but also for working older professionals ( 25 to 45 years old).

Fixation of achievements and their assessment are the most important components of the educational process. Providing students with feedback on the extent and how well they have mastered the subject is the main purpose of the assessment. At the same time, it should strengthen the learning process and not block the learner's independence, his creative and cognitive activity due to a drop in motivation when receiving a lower mark than expected. Any real process in the modern sphere of education can be achieved only with a combination of traditional education and online technologies [11].

Information and communication technologies in education are used at BMSTU, in particular when studying full-time students of the discipline "Technology of construction materials." This course generates professional knowledge, skills, and competencies in the field of design and manufacturing of technological machine parts. In the learning process, methods and methods of manufacturing blanks and their processing in gas-vapor, liquid, solid-liquid and solid states are considered.

Discipline allows students to gain practical skills in analyzing the manufacturability of the design of workpieces made by plastic deformation, powder metallurgy methods, 
casting, welding, subsequent machining, as well as changing the drawings of parts to increase their manufacturability, including in additive manufacturing [14, 16].

The purpose of the discipline is the development of the basic concepts, terms and definitions used in the design and manufacture of engineering products. Acquisition of basic knowledge about the physicochemical processes of smelting cast iron, steel and nonferrous alloys, manufacturing techniques for workpieces and their machining by cutting to create designed parts. At the same time, students should develop skills in designing technological parts of machines, taking into account the operational requirements for products and the current level of technology development.

\section{Online course "Technology of construction materials"}

\subsection{Course structure}

Work on the creation of an electronic course "Technology of structural materials" was started in 2010 at the department of "Technology of construction materials processing" at Bauman Moscow State technical University. The electronic course of lectures is based on the textbook A. Tretyakova "Technology of construction materials." Lecture course (with multimedia manual on an optical disk) [3].

The total complexity of the course: 144 hours (4 credits), 17 academic weeks. All training material is divided into three modules and 17 topics, the study of which is carried out at lectures and seminars. The study of theoretical material is fixed by performing tests to self-test knowledge on each topic. An example of test questions is presented in Figure 1.

\begin{tabular}{|c|c|}
\hline $\begin{array}{l}\text { What are the main stages of the technological process } \\
\text { of manufacturing and functioning } \\
\text { of machine-building products? } \\
\text { A) metallurgical production, Assembly, } \\
\text { maintenance, disposal; } \\
\text { B) procurement, billet processing, testing, repair } \\
\text { C) responses A and B } \\
\text { D) there is no correct answer. }\end{array}$ & $\begin{array}{l}\text { In what order are the processes of product design and } \\
\text { development of manufacturing technology carried out? } \\
\text { A) product design, development } \\
\text { of technological solutions; } \\
\text { B) development of technological } \\
\text { solutions, product design; } \\
\text { C) these processes occur simultaneously; } \\
\text { D) the sequence of these processes does not } \\
\text { matter }\end{array}$ \\
\hline $00: 45$ & $00: 45$ \\
\hline $\begin{array}{l}\text { What parameters are classified by structural steels? } \\
\text { A) chemical composition, amount of } S \text { and } R \text {, the } \\
\text { degree deoxidation, the graphite form; } \\
\text { B) form of graphite, strength, purpose, the number } \\
\text { of } S \text { and } P \text {, component location; } \\
\text { C) chemical composition, amount of S and P, degree } \\
\text { of deoxidation, structure, strength, purpose; } \\
\text { D) location of components, chemical composition, } \\
\text { degree of deoxygenation. }\end{array}$ & $\begin{array}{l}\text { What key factors determine physico-chemical, } \\
\text { mechanical, operational properties of metal machining } \\
\text { blanks? } \\
\text { A) structure of the main component atom, } \\
\text { atomic-crystal structure; } \\
\text { B) chemical composition; } \\
\text { C) macrostructure, microstructure; } \\
\text { D) all answers are correct. }\end{array}$ \\
\hline $00: 45$ & $00: 45$ \\
\hline
\end{tabular}

Fig. 1. Test case example. 


\subsection{Course assessment}

When studying the discipline, students are expected to complete 2 homework and 3 frontier controls, which are carried out online after the completion of each module, homework is protected in traditional form at seminars.

The developed course is a technological discipline, the study of which has a number of specific features. First of all, the physical and chemical foundations of such disciplines are based on natural science and applied disciplines, such as physics, chemistry, resistance of materials, materials science and several others. References to the main provisions of these disciplines, the use of terminology, notation, chemical formulas - all this complicates the presentation of the material.

In addition, technological processes, as a rule, are multivariate and multi-stage. Therefore, when describing and analyzing them, it is difficult to provide a visual representation of the individual elements and maintain a holistic perception. Moreover, any technological process is a complex system, including processing methods, equipment, equipment, tools and work pieces.

The course "Technology of structural materials" is intended to collect together disparate knowledge and establish the general laws of technological processes for the manufacture of machine parts with the required properties.

An important stage in the creation of the product is the design process, during which the designer introduces the optimal design and technological solution into the documentation. At the same time, it must meet operational requirements and meet the current level of technology development.

A feature of studying technological discipline online is a joint review of the design and manufacturing processes of workpieces and machine parts, which forms competences among students that contribute to the effective resolution of problem situations that arise when creating technological products.

In addition, the possibility of using numerous animations and video clips in the online course allows you to get a general idea about the transformation of the original work pieces from ore to products.

Placing the electronic course "Technology of structural materials" on the platform "Open BMSTU" allowed teachers and students to use the automatic assessment of knowledge gained. This feature allows teachers to work with large flows of students while not overloading them with monitoring of completed control tasks. The automatic assessment system offers tools for formative and final assessment: weekly tests and crosswords, as well as assessment of the results of studying individual modules and the whole discipline as a whole [4].

The system for evaluating the knowledge gained by students studying the TCM discipline includes: tests with answer options and crosswords. An example of a crossword puzzle is presented in Figure 2. To formulate the questions so that the assessment is of high quality - the work is difficult, it takes a lot of time. When developing a system for assessing students' knowledge, it is necessary to ensure that in the educational material of the course it is easy to find answers to all the questions contained in tests and crosswords [5]. 


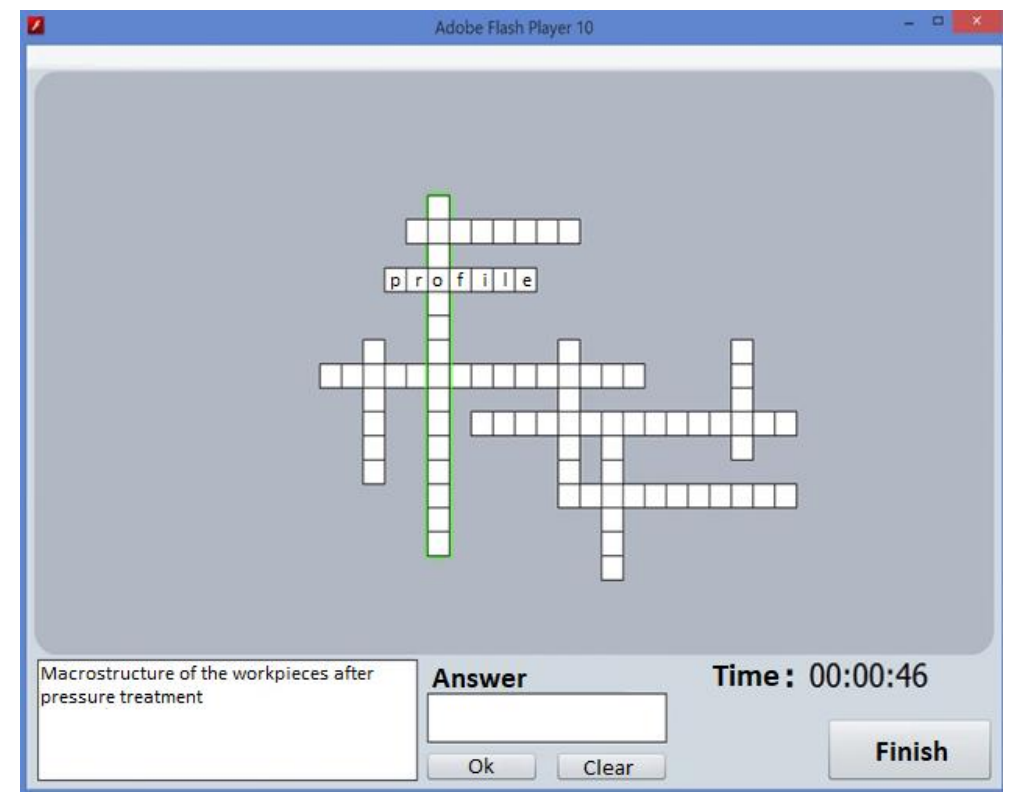

Fig. 2. Crossword Example.

After conducting trial testing and completing (solving) crosswords, the authors analyzed the results and corrected those questions, the percentage of correct answers to which on the first attempt is less than $70 \%$. Access to real-time data and the possibility of adjusting control tasks is one of the advantages of online courses hosted on the Open BMSTU platform.

When students study the online course "Technology of Structural Materials" (TCM), students' self-esteem is formed by weekly monitoring the material being studied using electronic crosswords. The work of students with crosswords in the study of educational material and the assessment of its assimilation online contributes [6]:

- the development of the conceptual and technological apparatus in the discipline under study, as well as the deepening, generalization, systematization and control of knowledge;

- he development of attention, associative creative thinking, the ability to work with various sources of information;

- increase educational motivation.

Creation of crosswords includes the following steps: information search, compiling a list of terms on the subject of educational material; compilation of questions for selected words, spell check of the text; Crossword design (in the text editor Microsoft Word, Microsoft Office Excel and Power Point, as well as using Internet crossword puzzles).

Thus, the use of testing and crosswords in the learning process stimulates the cognitive activity of students and the desire for independent mastery of knowledge.

At the same time, part of the work related to assessment is removed from the teacher. When the correct and incorrect answers are commented, the test with the answer choices itself becomes part of the training material. Similarly, solving crossword puzzles by students allows you to repeatedly study the lecture material, which allows you to form a self-esteem of the quality of knowledge gained. 
Testing is often seen solely as an assessment tool, but it also serves other purposes. For example, testing is more effective than additional study of material whose knowledge is being tested $[7,8]$.

Researchers in the field of teaching psychology [9] found that preliminary testing before starting training can help students familiarize themselves with important concepts that will be discussed in detail in the online course. The experimental results indicate that the effectiveness of the test as a learning tool may depend on the feedback that students receive after passing the test.

On the Open BMSTU platform, an automatic assessment of the results of the control measures of the course "Technology of Construction Materials" was established. To successfully complete the course, it is necessary to successfully complete 65 percent of all tests at the course.

The course contains two types of testing, the second is the midterm control. Current monitoring is carried out during the entire training period and usually amounts to 7-10 questions on one or two topics. Milestone control is carried out twice in the semester, in the middle of the course and at the end and is a volumetric testing of 30-40 questions on 6-8 topics. Successful completion of the process of intermediate control is possible only with regular work. To complete the course, the student must complete all control measures. The percentage of points for each type of testing is shown in Figure 3.

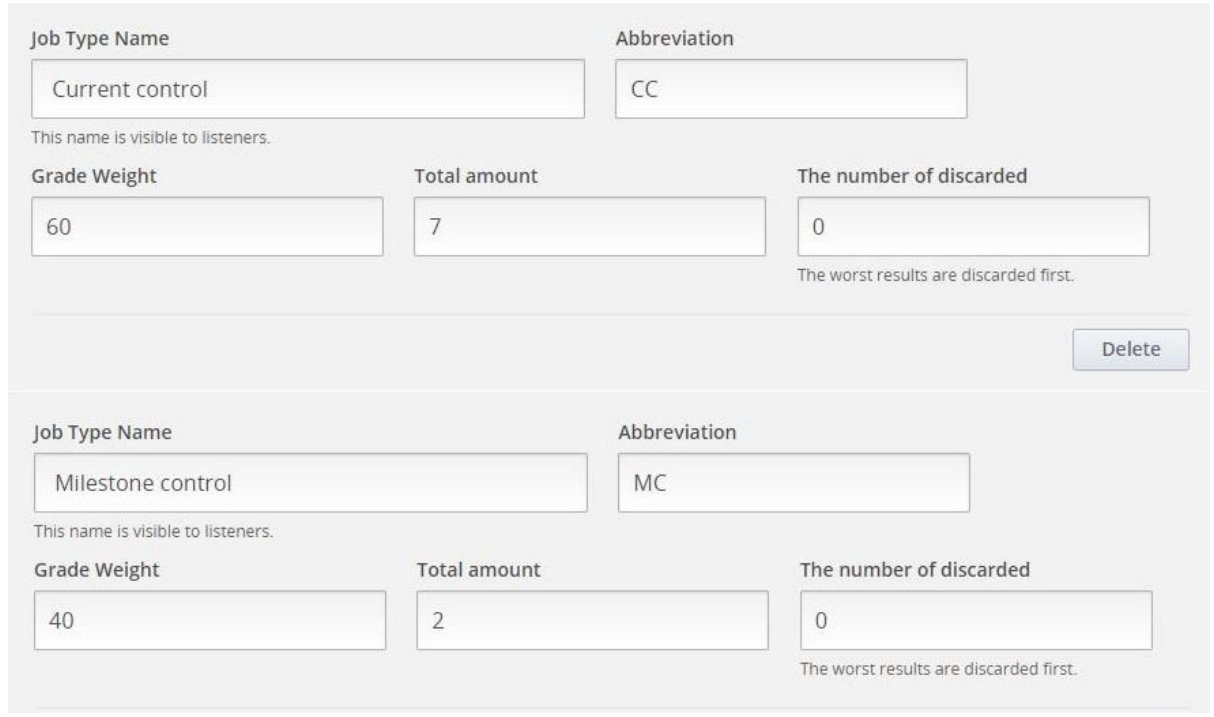

Fig. 3. Weighting coefficients of various types of assessment.

After completing the course, the student will be able to choose materials and methods of casting, pressure processing, welding and types of machining, taking into account the technical requirements for the manufactured product. After listening to the course, the student will have the skills to analyze the manufacturability of the design of workpieces and parts obtained by casting, pressure machining, welding and machining methods, as well as make changes to the design of the part in accordance with the requirements of manufacturability. 


\subsection{Using an online course}

An electronic course of lectures on the subject of TCM has been developed for use in lecturing streams in classrooms equipped with multimedia equipment (projector, television, interactive whiteboard, etc.). The electronic course of lectures is a slide lecture, i.e. a set of slides, animations, video clips that the teacher comments and explains. Such an electronic lecture course is posted as a training tool on the Open BMSTU platform, with one difference: instead of a "live" teacher, information is transmitted through a video lecture.

The course of lectures is accompanied by fixing seminars, which solve technological problems using Internet resources (patent databases, GOST databases, various online directories, websites of manufacturers of tools and engineering products, etc.) in real time, as well as consultations on implementation homework. Milestone controls are tests hosted on the Open BMSTU platform.

Students are tested using electronic learning tools such as a computer and even a telephone. Lectures and seminars are provided with additional media content (films, animated images, diagrams, drawings, etc.) for a more complete acquaintance with the technological processes under consideration. To create additional media content, we used: educational video materials, independently developed animated images and video clips, advertising materials and media content from the Internet.

The created online course on the Open BMSTU platform can be used in a traditional form of training for: checking students' knowledge after leaving their academic leave and helping students who cannot attend classes (lectures and seminars) for medical reasons.

Placing a full-fledged online TCM course on the "National Open Education Platform" is possible, for example, for students of the Faculty of Engineering Business and Management (IBM) studying in the direction of training "Innovation". The total complexity of the discipline is 2 credits, 17 academic weeks. All training material is divided into three modules and 17 topics, the study of which is carried out in lectures, which can be implemented using online courses. The theoretical knowledge gained is secured by students performing tests for self-testing on each topic and performing 3 boundary controls, which are carried out online after the completion of each module.

\section{Conclusions}

Thus, due to the lack of homework and seminars on the TCM course, the implementation of which requires a direct dialogue between the student and the teacher, this discipline can become a full-fledged online course that students can learn without the participation of the teacher.

Of course, this type of training is unacceptable for students in engineering and technological specialties, but may be in demand by students of other specialties (economics, management, ecology, etc.) who want to increase their level of technical literacy. To avoid confusion in the names, this course can be called "Fundamentals of the technology of structural materials" or simply "Fundamentals of TCM", which more accurately reflects its content.

In addition, it is advisable to place an open online TCM course for working professionals on the "National Open Education Platform" so that students can get tangible benefits from taking the course, for example, find a new job, advance in service, change employment, acquire skills allowing to improve the results of professional activity. At the same time, it is necessary to involve specialists: operators, graphic designers, experts in the field of education, designers of training courses, to finalize the considered electronic course of lectures. 


\section{References}

1. Ya.I. Kuzminov, M. Carnoy, Panel discussion, Online Learning: How It Affects the University Structure and Economics, Voprosy obrazovaniya, No. 3, pp. 8-43 (2015)

2. V. Gromyko, V. Kazaryan, N. Vasilyev, A. Simakin, S. Anosov, Artificial intelligence as tutoring partner for human intellect, Advances in intelligent systems and computing, № 658, pp. 238-247 (2018)

3. V. Mayorova, O. Zhdanovich, Innovative collaborative educational programs for space systems engineers, Proceedings of the International Astronautical Congress, IAC (2016)

4. G. Procurat, A. Strukova, A. Vukolov, O. Egorova, Generated graphics and game development software in engineering education: Perspectives and experience of usage, Mechanisms and Machine Science, № 64, pp. 123-130 (2019)

5. N. Serdyukova, V. Serdyukov, S. Neustroev, Testing as a feedback in a smart university and as a component of the identification of smart systems, Smart Innovation, Systems and Technologies, № 144, pp. 527-538 (2019)

6. V. Guznenkov, P. Zhurbenko, The Academic Discipline 'Computer Graphics' for the Open Education System, 2018 4th International Conference on Information Technologies in Engineering Education, Inforino 2018 - Proceedings 8581738 (2018)

7. A. Karpov, Education for knowledge society: Learning and scientific innovation environment, Journal of Social Studies Education Research, № 8(3), pp. 201-214 (2017)

8. E. Egorkina, M. Ivanov, N. Ivanov, N. Uchevatkina, Formirovanie nauchnoissledovatel'skikh kompetentsii studentov s primeneniem distantsionnykh obrazovatel'nykh tekhnologii i ehlektronnogo obucheniya, sbornik materialov XI Vserossiiskoi nauchno-prakticheskoi konferentsii «Tsifrovye tekhnologii $\mathrm{v}$ obrazovanii, nauke, obshchestve», pp. 52-55

9. A. Tretyakov, Tekhnologiya konstruktsionnykh materialov, Kurs lektsii: uchebnoe posobie dlya vuzov. MGTU im. N. E. Baumana (2010)

10. K.F. Deborah, Practices for Student Success: From Face-to-Face to At-Scale and Back, No. 4, pp. 116-138 (2018)

11. M. Janelli, E-Learning in Theory, Practice, and Research, No. 4, pp. $81-98$ (2018)

12. G. Selevenko, Ehntsiklopediya obrazovatelnykh tekhnologii, Vol. 1, pp. 350-553

13. L. Richland, N. Kornell, L.S. Kao, The Pretesting Effect: Do Unsuccessful Retrieval Attempts Enhance Learning, Journal of Experimental Psychology: Applied, Vol. 15, No. 3, pp. 243-257 (2009)

14. N. Kornell, M.J. Hays, R.A. Bjork, Unsuccessful Retrieval Attempts Enhance Subsequent Learning, Journal of Experimental Psychology: Learning, Memory, and Cognition, Vol. 35, No. 4, pp. 989-998 (2009)

15. J. Dunlosky, K.A. Rawson, E.J. March, M.J. Nathan, D.T. Willingham, Improving Students' Learning with Effective Learning Techniques: Promising Directions from Cognitive and Educational Psychology, Psychological Science in the Interest, Vol. 14, No. 1, pp. 4-58 (2013)

16. I. Horváth, Innovative engineering education in the cooperative VR environment, 7 th IEEE International Conference on Cognitive Infocommunications (CogInfoCom), 2016, pp. 359-364 (2016) 
17. C.Y. Chao, Y.T. Chen, K.Y. Chuang, Exploring students' learning attitude and achievement in flipped learning supported computer aided design curriculum: A study in high school engineering education, Computer Applications in Engineering Education, 23(4), pp. 514-526 (2015)

18. J. Gutierrez, C.E. Mora, B. Anorbe-Diaz, A. Gonzalez-Marrero, Virtual Technologies Trends in Education, Eurasia Journal of Mathematics, Science and Technology Education, 13(2), pp. 469-486 (2017)

19. A.P. Markopoulos, A. Fragkou, P.D. Kasidiaris \& J.P. Davim, Gamification in engineering education and professional training, International Journal of Mechanical Engineering Education, 43 (2), pp. 118-131 (2015)

20. S. Junk, R. Matt, Workshop Rapid Prototyping - a new approach to introduce Digital Manufacturing, engineering education Proceedings of 14th International Conference on Information Technology Based Higher Education and Training, ITHET, IEEE Xplore, Lisbon, Portugal, pp. 1-6 (2015)

21. M.L. Florence, D. Swamydoss, New revolution in education-digital classroom, Online Journal of Distance Education and e-Learning, № 5 (1), p. 66

22. M. Leary, M. Mazur, M. McMillan, M. Brandt, A. Subic, [DesktopLabs] Desktop Laboratories: Web Share and Additive Manufacture of Engineering Educational Models Procedia Technology, Vol. 20, pp. 111-116 (2015)

23. P.T. Goeser, F.G. Hamza-Lup, W.M. Johnson, D. Scharfer, VIEW: A virtual interactive web-based learning environment for engineering, IEEE Engineering Education Journal, Special Issue on Research on e-Learning in Engineering Education, pp. 1-24 (2011)

24. V. Potkonjak, M. Gardner, V. Callaghan, P. Mattila, Ch. Guetl, V. Petrović, K. Jovanovic, Virtual Laboratories for Education in Science, Technology, and Engineering: a Review, Computers \& Education, Vol. 95, pp. 309-327 (2016)

25. B. Kerr, The flipped classroom in Engineering Education: A survey of the research, Conference: Interactive Collaborative Learning, At Florence, Italy, pp. 815-818 (2015)

26. B. Gan, T. Menkhoff, R. Smith Smith, Enhancing students' learning process through interactive digital media: New opportunities for collaborative learning, Computers in Human Behavior, Vol. 51, Part B, October 2015, pp. 652-663 (2015)

27. C. Bodnar, D. Burkey, J. Enszer, D. Anastasio, Engineers at Play: Utilization of Games As Teaching Tools for Undergraduate Engineering Students, Journal of Engineering Education, No. 105 (1), pp. 147-200 (2014)

28. L. Braghirolli, J. L. Ribeiro, A. Weise, M. Pizzolato, Benefits of educational games as an introductory activity in industrial engineering education, Computers in Human Behavior, No. 58, pp. 315-324 (2016) 